\title{
Uma fenomenologia da imaginação através do espaço
}

\author{
Karina de Castilhos Lucena*
}

\begin{abstract}
Resumo: O objetivo deste ensaio é apresentar os principais conceitos de Gaston Bachelard na obra $A$ poética do espaço, expandindo-os a alguns textos da literatura produzida na América Latina, já que Bachelard utiliza autores europeus e norte-americanos em sua análise. Acredita-se que os textos tomados neste trabalho são também apropriados para ilustrar o pensamento bachelardiano, comprovando assim a universalidade das idéias do autor.
\end{abstract}

Palavras-chave: Fenomenologia; Espaço; Gaston Bachelard.

\begin{abstract}
Gaston Bachelar's main concepts from his work The poetics of space are introduced. Such concepts are extended to some texts from Latin America Literature since Bachelar included European and North Americans writers in his analisis. These selected texts are believed to throw some light on Bachelard's convictions, thus supporting the author's universality of ideas.
\end{abstract}

Keywords: Phenomenology; Space; Gaston Bachelard.

Tomar o espaço "como um instrumento de análise para a alma humana" (2005, p. 20). Com essas palavras, já enunciadas na introdução, Gaston Bachelard deixa claro o que pretende com o livro A poética do espaço. A obra configura-se como um tratado, extremamente poético, sobre as imagens desencadeadas a partir de diferentes espaços recorrentes na literatura: casa, porão, sótão, cabana, gaveta, cofre, armário, ninho, concha e canto.

O autor afirma que através do espaço se pode chegar a uma fenomenologia da imaginação, ou seja, conhecer a imagem em sua origem, em sua essência, sua pureza. Com essa afirmação, Bachelard, que é um fenomenólogo, mostra-se partidário dos estudos interdisciplinares, unindo Literatura, Filosofia e Psicologia.

A fenomenologia tem origem por volta de 1900 com o filósofo Edmund Husserl e, segundo Jean-François Lyotard, é o

estudo dos fenômenos, isto é, daquilo que aparece à consciência, daquilo que é dado. Trata-se de explorar este dado, a própria coisa que se percebe, em que se pensa, de que se fala, evitando forjar hipóteses, tanto sobre o laço que une o fenômeno com o ser de que é fenômeno, como sobre o laço que o une com o Eu para quem é fenômeno. (1999, p. 10).

A poética do espaço está dividido em onze capítulos que analisam, do maior para o

\footnotetext{
* Docente UCS.
} 
menor, diferentes espaços. Na Introdução, o autor faz algumas considerações sobre a imagem poética, dizendo que ela não é causada por impulsos do passado, como afirmam os psicólogos e psicanalistas, pelo contrário, ela tem "um ser próprio, um dinamismo próprio" (1993, p. 2) que merece a ontologia a qual se propõe o livro. Em outras palavras, quando se lê um texto literário, a imagem construída através dele tem significado em si mesma, no momento presente e de maneira distinta em cada leitor, que se torna neste momento também autor.

Bachelard, ao mesmo tempo em que se vale de diferentes disciplinas para chegar à fenomenologia da imagem, critica-as por não tomarem a imagem isoladamente. Conforme dito anteriormente, a psicologia e a psicanálise são criticadas por darem demasiada importância à causalidade. Mas também por desejar "incessantemente descrever os sentimentos" (1993, p. 8), no caso do psicólogo, ou por intelectualizar, tentar compreender, interpretar a imagem, no caso do psicanalista. O crítico literário também é alvo dos julgamentos do autor, que o considera "um leitor muito severo" (1993, p. 9), assim como o filósofo que está sempre tentando explicar o mundo como um todo, sem perceber que o mundo está nas pequenas coisas. Percebe-se, assim, que Bachelard é adepto da arte pela arte, do entregar-se completamente ao momento da leitura. Nas palavras dele, a arte é "uma reduplicação da vida, uma espécie de emulação nas surpresas que excitam a nossa consciência e a impedem de cair no sono" (1993, p. 17).

Ainda na Introdução, o fenomenólogo textualiza seu objetivo com esse livro: "examinar imagens bem simples, as imagens do espaço feliz" (1993, p. 19). Por isso a escolha de espaços íntimos (casa, quarto...) que participam da vivência humana desencadeando sentimentos e lembranças.

O primeiro capítulo, intitulado A casa. Do porão ao sótão. O sentido da cabana, trata a casa como "um verdadeiro cosmos" que é "o nosso primeiro universo" (1993, p. 24). A casa é o abrigo primordial do homem, ela o acolhe e o faz sonhar; na casa ele pode desfrutar a solidão. Segundo o autor "a casa é uma das maiores forças de integração para os pensamentos, as lembranças e os sonhos do homem" (1993, p. 26). Mesmo quando ela é humilde e cheia de defeitos, no devaneio torna-se reconfortante, dá estabilidade.

A partir dessa definição não há como não recordar o conto Casa tomada, de Julio Cortázar, no qual as personagens, dois irmãos, reduzem suas vidas ao cuidado com a morada que para eles certamente é o universo. Mais do que isso, na casa estão todas as lembranças da família, a casa é uma metáfora da família, e no momento em que ela é tomada se acaba a vida e a estirpe.

E é sempre a primeira casa que está mais fortemente arraigada no inconsciente. Ela 
congela as lembranças da infância, tornando-a contínua. E essa casa "deve guardar sua penumbra" (1993, p. 32), pois é através da penumbra, do indeterminado, que as imagens são criadas. Na casa natal descobre-se a função de habitar que será transplantada a todas as outras moradas, quando essa casa inicial já não mais existir.

Gabriel García Márquez, em Memória de minhas putas tristes, cria uma personagem que faz questão de passar toda a vida na mesma casa, onde consegue ficar só, onde estão as recordações de sua família e de sua infância, que são mais importantes do que o fato de não ter sido feliz naquele lugar.

Vivo numa casa colonial na calçada de sol do parque de San Nicolás, onde passei todos os dias da minha vida sem mulher nem fortuna, onde viveram e morreram meus pais, e onde me propus morrer só, na mesma cama em que nasci e num dia que desejo longínquo e sem dor (2005, p. 9).

E a questão da penumbra também é levantada, pois a personagem diz que "a única coisa ingrata na casa é que o sol vai mudando de janelas no transcurso do dia, e é preciso fechar todas elas para tratar de dormir a sesta na penumbra ardente" (2005, p. 10).

Há duas formas de se imaginar a casa: verticalmente ou centralizadamente. Através da verticalidade se chegará ao sótão e ao porão. O sótão está mais perto das nuvens, da racionalidade, logo vai gerar imagens claras. É o que acontece, por exemplo, com a personagem Licurgo Cambará, no segundo volume de $O$ continente de Erico Verissimo. Quando o estado de sítio impera no Sobrado, o único lugar em que ele consegue ter pensamentos bons é na água furtada, parte superior do casarão. É lá que ele recorda Ismália Caré:

Curgo abre de par em par a janela da água furtada, senta-se num mocho junto dela e debruça-se sobre o peitoril. A brisa úmida da manhã o envolve, dando-lhe a impressão de que mergulhou a cabeça na água fria dum açude. As faces e as orelhas lhe ardem, e ele aspira com força o ar que cheira a sereno e a campo. Pensa no Angico e em Ismália com uma saudade impaciente (2004, p. 171).

O porão é a parte mais obscura, irracional da casa; lá é noite todo o tempo, lá se sente medo. Voltando novamente a $O$ continente, são completamente diferentes as lembranças de Licurgo em relação ao porão do Sobrado; foi lá que ele enterrou a filha recém-nascida. O porão é o lugar dos mortos.

A outra maneira de imaginar a casa, através da centralidade, levará para o sentido da cabana. A casa é imaginada com toda a simplicidade, a primitividade, o aconchego de uma cabana. Ali se dá o encontro com a solidão, as lembranças viram lendas. A cabana representa a intimidade do refúgio.

Ainda na primeira parte da trilogia de Erico Verissimo, pode-se encontrar este sentido de centralidade quando o estrangeiro Carl Winter se sente acolhido pelo Sobrado: "Gostava 
[...] do Sobrado como dum velho amigo calado e acolhedor, que tudo dá e nada pede. Era a única casa daquela vila que lhe dava uma impressão de conforto, de abrigo" (2004, p. 99).

Casa e universo é o título do segundo capítulo do livro. É nessa parte do texto que Bachelard apresenta alguns espaços construídos por grandes escritores, dentre eles Baudelaire, Rilke, Henri Bosco, Edgar Allan Poe. O autor continua tratando a casa como um "centro de proteção" que se torna o "centro de um devaneio" (1993, p. 56). E a casa pode assumir dois papéis de proteção: um em que ela não luta e outro em que ela luta com o universo.

O exemplo que Bachelard toma para a casa que protege sem lutar, retirado de Baudelaire, é em uma situação de neve. A casa acolhe o homem do frio como uma mãe que envolve um cobertor nos ombros do filho. Por isso, segundo o autor, "o inverno [...] é um reforço da felicidade de habitar" (1993, p. 57). É nesse momento que se sente a maior alegria em ter onde abrigar-se do frio universal.

Já para tratar da casa que luta pela proteção, o autor vale-se de Henri Bosco. Em uma tempestade, a casa embrenha-se em uma luta defensiva por manter-se viva, protegendo assim o seu habitante. A imagem criada é novamente a de uma mãe que, "como uma loba" (1993, p. 61), ampara o filho contra a agressividade do universo manifestada na tempestade. Passada a tempestade e vencida a luta, "a choupana transformou-se em fortaleza de coragem para o solitário que nela deve aprender a vencer o medo" (1993, p. 62). Sendo assim, o heroísmo da casa passa a habitar o homem.

O padre Alonzo, no primeiro volume de $O$ continente, trata a igreja, que é a sua casa, como a mãe protetora que luta para protegê-lo: "Sim, aquela catedral lembrava-lhe a mãe. No verão seu ventre era fresco; mas como eram cálidas no inverno suas entranhas! E no dia em que os inimigos atacassem a redução [...] a catedral seria uma cidadela invencível" (2004, p. 46).

Na continuação do segundo capítulo, Bachelard opõe, à casa natal, a casa sonhada, que seria a última morada. Nessa casa caberia todo o conforto, a solidez e a comodidade não tidos na primeira casa. A casa final seria muito bem planejada, concreta, definitiva; seria também mais triste, pois a realidade afasta o devaneio. Na medida em que todas as fantasias da casa inicial tornam-se reais, não há mais porque sonhar.

Com esse pensamento, o autor propõe "uma ritmanálise da função de habitar" (1993, p. 78) que seria exatamente dar um maior valor aos pequenos ritmos da vida ao invés de apenas deixar-se levar pelos grandes ritmos do universo. Aqui cabe aquela velha máxima de que o homem deve preocupar-se mais em Ser e menos em Ter. Dessa forma, alguém pode 
habitar um castelo, mantendo a simplicidade e a intimidade da choupana.

O capítulo três: A gaveta, os cofres e os armários, inicia-se com uma crítica ao filósofo francês Henri Bérgson, que utilizou a palavra "gaveta" em sentido metafórico, como sinônimo de "conceito". Segundo Bachelard, as palavras, principalmente as da linguagem mais usual, têm um sentido poético próprio que é perdido quando transplantado para uma área científica ou filosófica. Exageros à parte, o autor parte dessa crítica para distinguir "metáfora" de "imagem".

Para ele, "a metáfora vem dar um corpo concreto a uma impressão difícil de exprimir" e acrescenta "a metáfora é relativa a um ser psíquico diferente dela" (1993, p. 87), ou seja, é uma transposição. A imagem, ao contrário, é “obra da imaginação absoluta, extrai todo o seu ser da imaginação" (1993, p. 87). Dito de outra maneira, a imagem é pura, é um fenômeno em si mesma, já a metáfora é uma "imagem fabricada" (1993, p. 88). Por isso somente a imagem pode ser objeto de um estudo fenomenológico.

Seguindo no terceiro capítulo, Bachelard afirma que "com o tema das gavetas, dos cofres, das fechaduras e dos armários, vamos retomar contato com a insondável reserva dos devaneios de intimidade" (1993, p. 91). Ele ajusta o foco de análise da casa para os objetos que a integram que são espaços de maior intimidade que a própria casa e por isso retêm traços psicológicos, possuem uma poesia singular.

No armário, assim como na gaveta, não se guarda uma coisa qualquer, segundo Bachelard somente um pobre de espírito poderia fazê-lo (1993, p. 91). Esses são espaços profundos, que registram a vida de quem os possui. Nos armários e nas gavetas reina a ordem e a harmonia adocicados pelo perfume de lavanda.

O cofre e a fechadura são ainda mais instigantes, pois estão envoltos pela neblina do esconderijo, guardam irreveláveis segredos. E quando esses espaços são adentrados, nada é conhecido; um novo mundo se abre, milhares de novas imagens. Todos esses espaços internos guardam os sonhos da alma humana: "quem enterra um tesouro enterra-se com ele" (1993, p. 100).

Chama-se $O$ ninho o quarto capítulo de A poética do espaço. O autor toma a imagem do ninho, bastante recorrente na literatura, e compara-a com a casa. A casa humana ideal é aquela tão aconchegante quanto o reduto dos animais. O habitante de uma casa-ninho sonha voltar para ela como o pássaro sonha voltar para o ninho (1993, p. 111), e nessa volta a alma se abre para infinitos devaneios. E a imagem do ninho é sempre pueril, devolve a infância, o encantamento, o gosto pela simplicidade; ainda que imaginado precário em sua estrutura o ninho traz sempre um devaneio de segurança. "O ninho é um buquê de folhas que canta" 
(1993, p. 115). Quando o homem consegue imaginar não só a sua casa, mas o mundo como um ninho, eles nunca se acabam.

Talvez o mais belo capítulo da obra de Bachelard seja A concha. A construção da morada com o calcário expelido pelo próprio organismo já é uma poesia. Por isso, as conchas passam uma imagem de vida que não se lança para frente, e sim gira sobre si mesma (1993, p. 118). A casa do molusco possui uma forma circular que faz mais do que apenas protegê-lo: é um espetáculo de beleza. Como a preocupação do fenomenólogo de imagens é sempre a simplicidade, a concha torna-se um fecundo objeto de estudo.

$\mathrm{Na}$ antiguidade, a concha foi símbolo do ser humano completo: a carapaça correspondia ao corpo; o molusco, à alma (1993, p. 127). E essa imagem traz uma esperança, afinal, se o ser mais mole pode fabricar a concha mais dura, por que o homem não pode fazer o mesmo? Mas é quando aceita a solidão que o homem realmente vive a imagem da concha. O sonho de morar sozinho, que cedo ou tarde habita em todos os seres humanos, nada mais é do que o desejo de ser envolto pela sua própria concha.

Bachelard diz, ainda neste mesmo capítulo, que "a casa que cresce na medida exata de seu hóspede, é uma maravilha do Universo" logo é um sublime motivo "de contemplação para o espírito" (1993, p. 129). E encerra afirmando que a imagem da concha é tão forte que até o biólogo Leon Binet descreve-a literariamente: "o caracol se retrai dissimuladamente em seu quiosque, como uma menina contrariada vai chorar no seu quarto" (1993, p. 132).

Os cantos são o assunto do sexto capítulo do livro. Eles, mais uma vez, permitem desfrutar a solidão ao mesmo tempo em que abraçam aqueles que neles se recolhem. É o que ocorre com a personagem principal do romance $O$ túnel, de Ernesto Sábato. Em um ambiente onde não conhece quase ninguém, e sentindo-se mal por causa disso, a única saída encontrada por Juan Pablo é "buscar refúgio em algum canto" (2000, p. 18).

O que caracteriza o canto é o silêncio, a imobilidade, a segurança. Nessa situação de quietude e aconchego, a alma fica aberta ao devaneio, e o canto se torna "um armário de lembranças" (1993, p. 151).

Finalizando o capítulo, Bachelard compara as palavras às casas para explicar o ofício do poeta. Os andares da habitação correspondem aos níveis de interpretação das palavras. Na página 155 , lê-se:

As palavras [...] são casinhas com porão e sótão. O sentido comum reside no rés-do-chão, sempre pronto para o "comércio exterior", no mesmo nível de outrem, desse transeunte que nunca é um sonhador. Subir a escada na casa da palavra é, de degrau em degrau, abstrair. Descer ao porão é sonhar, é perder-se nos distantes corredores de uma etimologia incerta, é procurar nas palavras tesouros inencontráveis. Subir e descer nas próprias palavras é a vida do poeta. 
No capítulo sete, Bachelard ajusta ainda mais o foco de análise priorizando os microespaços, que na verdade abrigam os macroespaços. Com o título de A miniatura, essa parte do texto ressalta o quanto é comum na literatura a narração de espaços pequenos para, a partir deles, intuir os grandes; segundo o autor “o grande [...] está contido no pequeno" (1993, p. 165).

Para comprovar o pensamento de Bachelard está Pablo Neruda, com suas Odes elementares, em que trata o vinho, o pão, o tomate, a cebola como verdadeiros universos. Abaixo se lê, na íntegra, pela beleza irresumível, a Ode à cebola

Cebola

Luminosa redoma

pétala a pétala

cresceu a tua formosura

escamas de cristal te acrescentaram

e no segredo da terra escura

se foi arredondando o teu ventre de orvalho.

Sob a terra

foi o milagre

e quando apareceu

o teu rude caule verde

e nasceram as tuas folhas como espadas na horta,

a terra acumulou o seu poderio

mostrando a tua nua transparência,

e como em Afrodite o mar remoto

duplicou a magnólia

levantando os seus seios,

a terra

assim te fez

cebola

clara como um planeta

a reluzir,

constelação constante,

redonda rosa de água,

sobre a mesa

das gentes pobres.

Generosa

desfazes

o teu globo de frescura

na consumação

fervente da frigideira

e os estilhaços de cristal

no calor inflamado do azeite

transformam-se em frisadas plumas de ouro.

Também recordarei como fecunda

a tua influência, o amor, na salada

e parece que o céu contribui

dando-te fina forma de granizo

a celebrar a tua claridade picada

sobre os hemisférios de um tomate.

Mas ao alcance

das mãos do povo

regada com azeite

polvilhada 


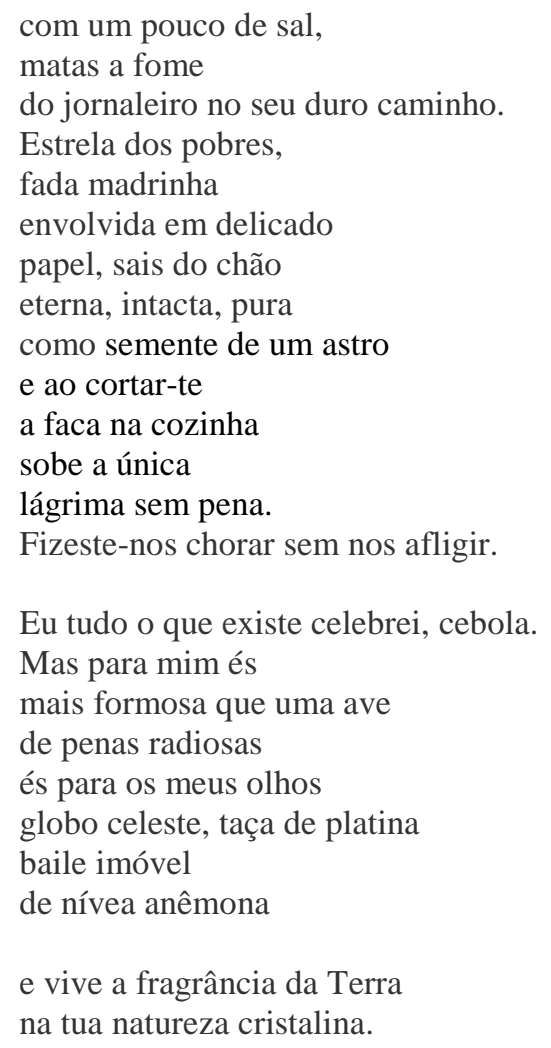

Nesse poema, Neruda utiliza uma miniatura, a cebola, para alcançar a magnitude do universo. Como ele mesmo diz nos últimos versos "vive a fragrância da Terra na tua natureza cristalina”.

E a explicação para que os grandes narradores adotem a descrição da miniatura é que "Todas as coisas pequenas exigem vagar. [...] É preciso amar o espaço para descrevê-lo tão minuciosamente como se nele houvesse moléculas de mundo, para enclausurar todo um espetáculo numa molécula de desenho" (1993, p. 167). Logicamente um autor que presa o vagar na narração também vai esperar o mesmo de seu leitor: que ele leia sem pressa e entre "no devaneio miniaturizante" (1993, p. 168). Através da miniatura, o escritor fala do mundo “sem se arriscar muito" (1993, p. 168).

Os espaços miniaturizados não podem ser vividos, como a casa, o quarto. Eles são somente imaginados. Quando o escritor cria um espaço de miniatura ele apela para os sentidos de seu leitor: ele vê, escuta, sente esse espaço através de seu devaneio.

Da idéia de miniatura, Bachelard passa para a de intimidade, no capítulo oito, que se chama $A$ imensidão íntima. O autor afirma, basicamente, que o homem, ao deparar-se com a imensidão transforma-a em intimidade, pois o devaneio é sempre particular. Não é possível atingir o imenso senão pelas experiências íntimas de cada um; "a imensidão está em nós" (1993, p. 190) e "a grandeza progride no mundo à medida que a intimidade se aprofunda" (1993, p. 200). 
No capítulo nove, A dialética do exterior e do interior, Bachelard critica essa dialética reafirmando o que vinha dizendo anteriormente: o exterior somente é entendido quando transformado em interior, e não pensar dessa forma leva a generalizações descabidas. Tudo é valor humano; o espaço não pode ser unicamente exterior pois é vivido, imaginado, recordado interiormente. "O exterior não será uma intimidade antiga perdida na sombra da memória?" (1993, p. 232).

No último capítulo, Bachelard apresenta A fenomenologia do redondo, que na verdade está diluída em todo o livro. As imagens circulares concentram, centralizam a vida, dão unidade, em oposição às pontiagudas que ferem, afastam. Assim as imagens que trazem segurança, aconchego, são todas redondas, o que fez Joë Bousquet escrever: "Disseram-lhe que a vida era bela. Não! A vida é redonda” (1993, p. 235).

Por fim, o livro de Gaston Bachelard constitui um caso de amor pela literatura e mais especificamente pelo espaço, levando Antonio Dimas a afirmar que o mais envolvente no estudo feito pelo autor "é a junção feliz entre rigor científico e experiência pessoal nunca descartada, confluindo ambos os vetores para associações surpreendentes e reminiscências arquetípicas do ser humano" (1985, p. 44).

\section{Referências}

BACHELARD, Gaston. A poética do espaço. São Paulo: Martins Fontes, 1993.

CORTÁZAR, Julio. Casa tomada. In: Cuentos completos. Madrid: Alfaguarra, 1994.

DIMAS, Antonio. Espaço e romance. São Paulo: Ática, 1985.

LYOTARD, Jean-François. A fenomenologia. Lisboa: Edições 70, 1999.

MÁRQUEZ, Gabriel García. Memória de minhas putas tristes. Rio de Janeiro: Record, 2005.

NERUDA, Pablo. [s.d.]. Ode à cebola. Disponível em http://www.adur-rj.org.br/5com/popup/ode_a_cebola.htm. Acesso em 17 nov 2006.

SÁBATO, Ernesto. O túnel. São Paulo: Companhia das Letras, 2000.

VERISSIMO, Erico. O continente I. São Paulo: Companhia das Letras, 2004.

VERISSIMO, Erico. O continente II. São Paulo: Companhia das Letras, 2004. 